\title{
UMA ABORDAGEM CARTOGRÁFICA PARA A INFÂNCIA: MEDIAÇÃO CULTURAL E CONSTRUÇÃO DE SENTIDOS
}

\author{
Daniela Cristina Viana ${ }^{1}$ \\ Silvia Sell Duarte Pillotto ${ }^{2}$ \\ Jane Mery Richter Voigt ${ }^{3}$
}

\begin{abstract}
Resumo
Este artigo apresenta uma pesquisa cujo objetivo foi desvelar sentidos construídos a partir da mediação cultural para a infância, tendo como fio condutor a abordagem teórica e metodológica da cartografia. As ações foram realizadas num espaço da educação infantil da rede pública de um município na região norte de Santa Catarina, com crianças de 4 a 5 anos. A pesquisa, de cunho qualitativo, foi realizada por meio de mediações culturais contemplando as linguagens/expressões das artes (dança, música e artes visuais) tendo como base uma Mostra, composta por fotografias de obras e objetos de um artista local, inseridas no acervo de um museu. $\mathrm{O}$ processo de pesquisa revelou pistas referentes às construções de sentidos pelas crianças, como: a ampliação da escuta dos sons produzidos de forma individual e coletiva; a identificação das dimensões visuais como curto/comprido, fino/grosso, largo/estreito, vazio/cheio, leve/pesado, volume, e a relação do corpo com o espaço, com outros corpos, com o movimento e com os ritmos musicais.
\end{abstract}

Palavras-chave: Práticas Educativas; Cartografia; Mediação Cultural.

\section{A CARTOGRAPHIC APPROACH TO CHILDHOOD: CULTURAL MEDIATION AND CONSTRUCTION OF SENSES}

\begin{abstract}
\footnotetext{
${ }^{1}$ Mestre em Educação pela Universidade da Região de Joinville. Pesquisadora do Núcleo de Pesquisa em Arte na Educação da Universidade da Região de Joinville e técnica administrativa em Educação do Instituto Federal de Educação, Ciência e Tecnologia de Santa Catarina. E-mail: daniela.ifsc@gmail.com

${ }^{2}$ Pós-Doutora pelo Instituto Estudos da Criança da Universidade do Minho - Braga/Portugal. Professora-pesquisadora do Mestrado em Educação e coordenadora do Núcleo de Pesquisa em Arte na Educação da Universidade da Região de Joinville-SC. E-mail: pillotto0@gmail.com

${ }^{3}$ Doutora em Educação, área de concentração Psicologia da Educação, pela Pontifícia Universidade Católica de São Paulo. Professora do Mestrado em Educação e pesquisadora do Núcleo de Pesquisa em Arte na Educação da Universidade da Região de Joinville-SC. E-mail: janevoigt@terra.com.br
} 
The objective of this article was to unveil senses constructed from cultural mediation for childhood, taking the theoretical and methodological approach of cartography as a conducting wire. The actions were carried out in an area of early childhood education of the public network in a municipality in the northern region of Santa Catarina, with children aged from 4 to 5 years of age. The qualitative research was carried out through cultural mediations contemplating the languages / expressions of the arts (dance, music and visual arts) based on an Exhibition, consisting of photographs of works and objects of a local artist, inserted in a museum collection. The research process revealed clues regarding the construction of senses by children, such as: the amplification of listening to sounds produced individually and collectively; the identification of visual dimensions as short / long, thin / thick, wide / narrow, empty / full, light / heavy, volume and body relation to space, other bodies, movement and musical rhythms.

Keywords: Educational Practices; Cartography; Cultural Mediation

\section{UN ABORDAJE CARTOGRÁFICO PARA LA INFANCIA: MEDIACIÓN CULTURAL Y CONSTRUCCIÓN DE SENTIDOS}

\section{Resumen}

Este artículo presenta una investigación cuyo objetivo fue desvelar sentidos construidos desde la mediación cultural para la infancia, teniendo como hilo conductor el abordaje teórico y metodológico de la cartografía. Las acciones fueron realizadas en un espacio de la educación infantil de la red pública de un municipio en la región norte de Santa Catarina, con niños de 4 a 5 años. La investigación, de cuño cualitativo, fue realizada por medio de mediaciones culturales contemplando los lenguajes/expresiones de las artes (danza, música y artes visuales) teniendo como base una Muestra, compuesta por fotografías de obras y objetos de un artista local, insertadas en el acervo de un museo. El proceso de investigación reveló pistas referentes a las construcciones de sentidos por los niños, como: la ampliación del oír de los sonidos producidos de forma individual y colectiva; la identificación de las dimensiones visuales como corto/largo, fino/grueso, largo/estrecho, vacío/lleno, liviano/pesado, volumen, y la relación del cuerpo con el espacio, con otros cuerpos, con el movimiento y con los ritmos musicales.

Palabras clave: Prácticas Educativas; Cartografía; Mediación Cultural 


\section{INTRODUÇÃO}

O presente artigo tem como proposta apresentar algumas questões conceituais e metodológicas da pesquisa intitulada "Uma abordagem cartográfica para a infância: mediação cultural e construção de sentidos", cujo objetivo foi desvelar sentidos construídos a partir da mediação cultural para a infância, tendo a abordagem cartográfica como fio condutor.

O campo de pesquisa escolhido foi um Centro de Educação Infantil (CEI) da rede municipal de educação situado na região norte de Santa Catarina. No CEI foram realizadas ações de mediação cultural com crianças entre 4 e 5 anos, contemplando mediações culturais nas linguagens/expressões das artes (dança, música e artes visuais), tendo como base uma mostra composta por fotografias de obras e objetos de um artista local.

Nossa trajetória como pesquisadoras/cartógrafas foi constituída de conhecimentos e experiências no campo das artes, em linguagens/expressões diferenciadas. Logo, percebemos que tratar das artes no universo infantil é compreendê-las de forma integrada, nos mais diversos sentidos e sensibilidades.

Vimos a possibilidade de desenvolvermos juntas as mediações, num movimento de (entre)laçamentos. E assim, muitas experiências aconteceram a começar pela construção de uma curadoria, que culminou na mostra artística na educação infantil, implicando muitas conversas permeadas por dúvidas e inquietudes. Desse modo, nossa pesquisa ampliava possibilidades metodológicas na educação, mergulhando num outro mar, que, embora turbulento, é ao mesmo tempo encantador, a cartografia.

Por meio do método cartográfico, tínhamos o aval de percorrer caminhos outros, trajetos que ora inventávamos, ora éramos submetidas por intermédio do nosso "[...] mapa do maroto" (ROWLING, 2000, p. 159). Ou seja, trabalhávamos com o imprevisível, sem deixar de lado o planejamento e a sua preparação.

Segundo Geertz (1989), mediar culturas significa mediar sentidos e significados de como interpretamos o mundo, o outro e a nós mesmos. Como nos fala Martins (2012a, p. 16), “[...] nestas redes de significações e de incertezas está a arte, ela mesma multiplicadora de sentidos [...]". Logo, referimo-nos ao processo/percurso que envolve sentidos e significados, que podem transformar o processo de mediar. Nos dizeres de Barbosa (2009), por intermédio da arte é possível desenvolver a percepção e a imaginação para aprender a perceber e interagir com o meio, ampliando a capacidade crítica, os processos de criação e a sua percepção de vida.

Em síntese, a educação em tempos atuais necessita de múltiplas abordagens, uma vez que labuta a cada dia com um público multifacetado em locais educacionais e demais contextos. 
Nessa perspectiva e com base também em nossas histórias como professoras/cartógrafas, pensamos que a arte pode contribuir e fornecer subsídios para práticas educacionais e culturais diferenciadas. Em nossa pesquisa, para tecer essa trama que ultrapassa os fios da educação e que se emaranha com a vida, é preciso de certos agentes como agulhas e fios: fios de criatividade, de conhecimento, de vontade, de motivação, de lugares, de tempo, de pessoas, de sentir e de sentido. E principalmente, fios metodológicos que permitam e suportem essas tramas, como o método cartográfico.

Como desafio, esta pesquisa teve a seguinte questão norteadora: como pensar e fazer mediação cultural na educação infantil, tendo a cartografia atravessada pelas linguagens/expressões da arte na construção de sentidos?

$\mathrm{O}$ artigo ora apresentado iniciará o diálogo pelo método cartográfico, seguindo com as experiências da pesquisa, adentrando por vias da curadoria, da mostra e da mediação cultural. Nessa trajetória estão atreladas as linguagens/expressões das artes, num constante movimento das crianças, dos professores e das pesquisadoras/cartógrafas.

\section{MÉTODO CARTOGRÁFICO: UMA TRAJETÓRIA COM MUITOS CAMINHOS}

O método cartográfico, “[...] incomum, e por isso mesmo bem-vindo como a chuva que remove a secura das coisas" (CAPOZZOLI apud MALDONATO, 2012, p. 14), surgiu nesta pesquisa como um alento aos perdidos em ideias contraditórias, narrativas e pistas preciosas. Pistas como cacos ou pedaços, apenas indícios de algo ou de caminho, desdobrando-se em pistas de algo, que descreviam caminhos ora tortuosos, ora suspirantes, ora sinfônicos como a quarta de Mozart. As pistas no percurso da nossa pesquisa ganharam sentido em caminhos traçados num mapa coletivo de narrativas e experiências compartilhadas. Caminhamos como aprendizes, e é nesse âmbito de incompletude que o presente artigo lança seu voo sobre territórios repletos de magia e aventuras.

A cartografia, como método de pesquisa, consiste em criar mapas de efeitos e de processos, o que exige do pesquisador/cartógrafo uma imersão no plano da experiência, onde conhecer e fazer se tornam inseparáveis (PASSOS; BARROS in PASSOS; KASTRUP; ESCÓSSIA, 2014). Ao passo em que experiências acontecem, num constante devir, inevitavelmente, o mapa sofre alterações, nesse sentido, o método cartográfico "trata-se sempre de investigar um processo de produção" (KASTRUP in PASSOS; KASTRUP; ESCÓSSIA, 2014, p.32).

Nesse caminhar, no plano da experiência, a pesquisa adentrou em vales da subjetividade, 
frutíferos e fecundos, convidando nossos olhares, corpos e mentes para passar um tempo com crianças pequenas entre 4 e 5 anos no contexto de um CEI, a propor-lhes as linguagenslexpressões das artes que vibraram suas cordas, convidando o corpo, a música e o visual para compor parte desse cenário.

Foi preciso então cultivar um lugar para construir sentidos com a experiência, e não sobre ela. Como dizem Alvarez e Passos (in PASSOS; KASTRUP; ESCÓSSIA 2014, p. 144), “[...] a investigação é cuidado ou cultivo de um território existencial no qual o pesquisador e o pesquisado se encontram”. Foram muitas as idas e vindas, foram muitas as narrativas dos personagens encontrados e descobertos nesse conto-pesquisa, pesquisa-percurso, percursocaminho, caminho-aventura, aventura-ciência.

Nesse sentido, nossa tarefa como pesquisadoras/cartógrafas consistiu em “[...] dar língua para afetos que pedem passagem" (ROLNIK, 2016, p. 23). E se a cartografia se dá no processo em que acontecem os afetamentos, nas mediações, ela se fez ao mesmo tempo em que "[...] certos afetos [foram] revisitados (ou visitados pela primeira vez)" (ROLNIK, 2016, p. 26).

O território, na pesquisa cartográfica, está além de localizações em mapas tradicionais, não é o do CEI, mas sim o território subjetivo no qual as crianças passaram sutilmente de um coletivo de gente, para partícipes de experiências ora produzidas e experienciadas por elas. Os territórios se constituem como um lugar de passagem, onde professoras orientadoras não estavam totalmente no lugar-sentido de autoridade, mas escapando entre as ações de mediação, vivenciando outras possibilidades. Foram deslocamentos territoriais de sentidos (ROLNIK, 2016). Um jogo de tantos fatores e dizeres que nos fez refletir sobre a escolha do método cartográfico, que movimenta mente, corpo e afeto. Talvez pela imprecisão ou também pelo caráter interventivo. Imprecisão no envolvimento dos sentidos, afetamentos e experiências, sempre incompletos e de infinitos desdobramentos, ou podemos dizer infinitos caminhos? E intervenção, porque a cartografia ao mesmo tempo em que é um método de pesquisa, pelo termo tradicional "como fazer" é também pesquisa-intervenção "fazer-saber, saber-fazendo". A pesquisa por esse método não se restringe a apenas descrever os contornos formais dos objetos do mundo, mas principalmente em traçar o movimento próprio que os anima. Nesse sentido,

intervir, então, é fazer esse mergulho no plano implicacional em que as posições de quem conhece e do que é conhecido, de quem analisa e do que é analisado se dissolvem na dinâmica de propagação das forças instituintes característica dos processos de institucionalização. (PASSOS; BARROS in PASSOS; KASTRUP; ESCÓSSIA, 2014, p. 26). 
Os caminhos da pesquisa foram, pouco a pouco, tornando-se complexos. Foi necessário narrar e fruir. Por meio desse preceito circundante percebemos que a todo o momento a experiência estava como principal mobilizador de subjetividades e afetamentos.

Para Passos e Barros (in PASSOS, KASTRUP E ESCÓSSIA, 2014, p. 31), “conhecer o caminho de constituição de dado objeto equivale a caminhar com esse objeto, constituir esse próprio caminho, constituir-se no caminho. Esse é o caminho da pesquisa-intervenção”.

“As cartografias vão se desenhando ao mesmo tempo (e indissociavelmente) em que os territórios vão tomando corpo: um não existe sem o outro" (ROLNIK, 2016, p. 46). Podemos chamar de cartógrafo o pesquisador, em nosso caso, aquele em que o olhar acompanha, estuda, define o seu trabalho em acompanhar os meandros dessa produção sentidos, dessa fuga de sentidos que escapam criando outros sentidos, outros territórios.

Podemos dizer que como pesquisadoras/cartógrafas fomos verdadeiras antropófagas, pois como fala Rolnik (2016), expropriamos, apropriamos, devoramos e desovamos; transvaloramos o que aconteceu nas mediações, por meio das linguagens/expressões das artes. Tornamo-nos pesquisadoras/cartógrafas com muita fome e sede, buscando elementos/alimentos para compor as cartografias da infância, as cartografias do acontecido envolvendo as crianças de 4 e 5 anos no CEI. A busca desses elementos consiste em escolhas, cujo critério é:

[...] descobrir que matérias de expressão, misturadas a quais outras, que composições de linguagem favorecem a passagem das intensidades que percorrem seu corpo no encontro com os corpos que pretende entender. Aliás, "entender", para o cartógrafo, não tem nada a ver com explicar e muito menos com revelar. [...] O que há [...] por todos os lados são intensidades buscando expressão. E o que ele quer é mergulhar na geografia dos afetos e, ao mesmo tempo, inventar pontes para fazer a travessia: pontes da linguagem. (ROLNIK, 2016, p. 65-66).

Sendo assim, o método da pesquisa estava em quem ou o que nele se constituiu e se afeta no percurso. A “[...] cartografia como método de pesquisa é o traçado desse plano da experiência, acompanhando os efeitos (sobre o objeto, o pesquisador e a produção do conhecimento) do próprio percurso da investigação" (PASSOS; BARROS in PASSOS; KASTRUP; ESCÓSSIA, 2014, p. 18). Não há como prever/saber a priori o destino que vamos alcançar; os resultados são cunhados no caminho, nas intervenções, no processo e na construção da própria pesquisa. É por isso que preferimos falar sobre pistas, indícios que movem o pesquisador. O cerne da pesquisa cartográfica está na processualidade que forma os contornos das discussões.

[...] a ocupação de um território numa pesquisa não se pode ser iniciada com um problema fechado, sabendo de antemão o que se busca. Tal posicionamento fecha 
o encontro com a alteridade do campo territorial, permitindo muitas vezes só encontrar o que já se sabia ou, o que é muito pior, não enxergando nada além dos seus conceitos e ideias fixas. Portanto, para o aprendiz-cartógrafo, o campo territorial não tem a identidade de suas certezas, mas a paixão de uma aventura. (ALVAREZ; PASSOS in PASSOS; KASTRUP; ESCÓSSIA, 2014, p. 138).

A pesquisa cartográfica por si só é inconclusiva e não dá conta de todas as questões que na caminhada vão se desdobrando, se complementando, se encontrando e, por vezes, se distanciando. Logo, trata-se de método que mais se aproxima do perfil da pesquisa que se constitui e se embocou na vontade/desejo de suas pesquisadoras. Além disso, falar de mediação cultural por meio das artes como possibilidade de construção de sentidos na infância implica transitar entre enredos outros que tornaram o processo complexo, certamente incompleto e consequentemente multidisciplinar.

Mas, quais são os procedimentos do cartógrafo? "Ora, estes tampouco importam, pois ele sabe que deve 'inventá-los' em função daquilo que pede o contexto em que se encontra" (ROLNIK, 2016, p. 66). E no contato com as crianças, reinventamo-nos e reinventamos ações ao passo que respostas por parte das crianças eram percebidas, em seus rostos (olhares, expressões), suas falas (perguntas, silêncios, comentários), seu corpo (agitação, imobilidade, gestos), no tempo de reação, no coletivo como a revoada de pássaros para outros espaços, buscando climas mais favoráveis.

Conforme os territórios em que nós pisávamos, foi preciso obter referências e olhares múltiplos sobre os conceitos elencados, envolvendo: práticas educativas, arte, educação não formal, mediação cultural, infâncias. Uma façanha complexa que a pesquisa de viés qualitativo tem fôlego para realizar. De tal modo, buscamos em Flick (2009) e Minayo (2015) sustentação teórica acerca da pesquisa qualitativa em educação. Para Flick (2009, p. 20), por exemplo, “[...] a pesquisa qualitativa é de particular relevância aos estudos das relações sociais devido à pluralização das esferas da vida”. Essa pluralização exige sensibilidade para o seu estudo, estamos falando de novas e velhas fronteiras de se lidar com a vida.

É interessante destacar que, embora no método cartográfico sejamos livres para criar, ele mantém seu rigor científico, porém de outra forma. Segundo Tordino (2014, p. 24), “[...] a liberdade e o rigor não se opõem, como antagônicos [...]. Liberdade é [...] uma espécie de atributo do rigor, que dela precisa por querer-se livre, em sua rigorosidade, para não se tornar rígido".Dessa forma, o pesquisador precisa estar submerso na pesquisa, embebido em sua metodologia, para então dar possibilidade a novos encontros e tramas que poderão melhor articular a pesquisa e, assim, proporcionar a ela o devido rigor. Quanto a investigar seus meandros e dar-lhes consistência, somente no mergulho livre de um aventureiro pesquisador é 
possível alcançar o aprofundamento prático-teórico-prático.

\section{CURADORIA: QUE CAMINHO É ESSE?}

Continuando nosso percurso, encontramo-nos e mergulhamos na curadoria, que em sua terminologia vem do latim curator, oris, que significa tutor. Para Chiarelli (1998, p. 12), o curador/tutor "[...] é sempre o primeiro responsável pelo conceito da mostra a ser exibida, pelas escolhas das obras, da cor das paredes, iluminação, etc.”. Segundo Martins (2012b, p. 28), os curadores ou museólogos “[...] são responsáveis pela seleção e organização do acervo [e] por criarem condições para a recepção ao olhar em todos os níveis [...]”.

E quais são seus atributos? "O que mais fazem é olhar a arte e pensar sobre a sua relação com o mundo" (LEONZINI apud OBRIST, 2010, p. 11). Tal processo não é feito de escolhas apanhadas ao vento. Para chegar a uma mostra ou exposição, o curador precisa tomar inúmeras e difíceis decisões, como a escolha de obras/objetos. Necessita percorrer espaços investigando possibilidades e efeitos, provocando-se ao modo forense. Isso significa que a curadoria tem intencionalidades e um ponto de vista, inventividade e diálogo.

O curador é um agente do processo artístico que influencia o que pode ser mostrado e, como não é um mero "mostrador", atua no efeito da arte quando encoraja isso e não aquilo. E na educação como "ter essa consciência fazia parte de olhar a arte e entender como se dão as opções artísticas. [...] Como tornar mais visíveis essa dimensão por trás do processo de seleção e de exposição pública da arte?” (SIEGELAUB apud OBRIST, 2010, p. 164).

$\mathrm{Na}$ educação a curadoria pode ser pensada pelo professor, que orquestra suas ideias, seus estudos e seu conhecimento, dando visibilidade às produções de crianças e adolescentes. Portanto, nosso processo de pesquisa contou com um mergulho profundo nas águas da curadoria no contexto da educação infantil, fundamentando-nos em Chiarelli (1998), Obrist (2010), Demarchi (2003), Leite e Ostetto (2005), Kastrup (1999), Boff (1997), Martins (2005, 2012b), entre outros.

$\mathrm{Na}$ curadoria, diálogos apontavam-nos caminhos outros que nos tiravam algumas vezes da zona de conforto, mobilizando-nos a andar como andarilhos, tateando por caminhos obscuros. Nesses momentos de troca, muitas ideias, confrontos, acertos e desacertos aconteceram. Encontros de aprendizes, de experiências, de silêncios, de ser e de estar presente em sentidos e significados. A cada encontro, novos recomeços, novas descobertas e aprendizados de pura sensibilidade!

A partir do projeto de curadoria, outro desafio estava lançado: organizar uma Mostra, que 
pudesse dialogar e convidar crianças de 4 e 5 anos a imergir em nossas mediações. Uma pista: pensamos que a Mostra poderia ter como referência a vida/obra de um artista local, que viveu e morou na casa que é hoje um Museu Casa.

Para isso, selecionamos no acervo do Museu Casa dez fotos/imagens de algumas obras e objetos pessoais do artista, bem como de monumentos, que fazem parte da paisagem de nossa cidade. A escolha das fotos/imagens teve como critério possíveis articulações com as três linguagens/expressões - visual, sonora e corporal -, buscando nas mediações culturais uma perspectiva multidisciplinar.

No movimento de pensar a curadoria, organizamos um texto, enfatizando alguns aspectos da Mostra, como: tema, envolvidos no projeto, parcerias e finalidade. Pista novamente: a ideia foi socializar com a comunidade escolar a intencionalidade da Mostra, valorizando um artista e a arte local como meio de construção de identidades. Nesse intuito, o texto cumpre o papel de oferecer elementos ou informações sobre um conjunto de fotos/imagens, a fim de aguçar os sentidos e o interesse do visitante de uma Mostra e ao mesmo tempo provocar a experiência estética (DEMARCHI, 2003).

E o que dizer então da experiência com curadoria? O que aprendemos? Estivemos em estados de invenção. Em processo e movimento. A curadoria hoje é por nós entendida como prática de socialização e mediação de saberes e carrega de potência as experiências de aprendizagem (KASTRUP, 1999). Aguçamos nossos sentidos para com a curadoria e podemos dizer que tivemos uma experiência estética. Nesse caso, a curadoria pode cumprir um papel de mediação entre as obras (aqui as fotos/imagens) e o observador/criança/adultos. Exerce também uma função pedagógica a favor da construção de sentidos sobre imagens, sons e corpos que tencionam e se movimentam, que se aproximam ou recuam, não importa. O que importa é a experiência (LEITE; OSTETTO, 2005).

\section{PREPARANDO O TERRITÓRIO}

Desejávamos uma Mostra que movimentasse as crianças. Um lugar de encontros, corpos e sentidos, que aos poucos transitou da ideia para o papel (curadoria) e do papel para o espaço do CEI. Uma pista: tínhamos de priorizar o olhar das crianças.

Foi pensando assim que organizamos as fotos/imagens na altura em que os olhos das crianças pudessem ver e onde suas mãos pudessem tocar. Entendíamos naquele instante que o curador faz o papel de comissário de exposições, que é a pessoa responsável pela concepção, montagem e supervisão de uma Mostra (CHIARELLI, 1998). "Significa esforçar-se para não 
enfatizar a própria subjetividade e deixar a arte mesma estar no centro. O poder verdadeiro, que é o único pelo qual se deve lutar, é o poder da própria arte” (BIRNBAUM apud OBRIST, 2010, p. 291-292).

A responsabilidade estava declarada, nossas concepções para a prática da mediação cultural dependiam da curadoria, dando sentido para a Mostra. Segundo Birbaum (apud OBRIST, 2010, p. 292), “[...] trata-se de esquecer tudo o que você pensa saber, e mesmo de se permitir perder-se". Isso nos lembra Alves (1994, p. 45) quando diz que "a educação pode ser um feitiço que nos faz esquecer o que somos, a fim de nos recriar à imagem e semelhança de um Outro". Ou aproximando de nossas questões de pesquisa: “[...] é preciso esquecer o aprendido que nos fez adultos para se ver o mundo com novos olhos" (ALVES, 1994, p. 53).

Com a música, as artes visuais e o movimento/dança, pretendíamos oportunizar experiências significativas para as crianças. Estávamos pensando em um devir, em uma construção mental, sensível e cognitiva que possivelmente não seria demonstrada no primeiro ato desse enredo/peça. Sabíamos nós que a mediação cultural envolvendo crianças pequenas era um desafio.

A preparação para as mediações culturais com base na Mostra contou com diversos momentos e ações. Uma das pesquisadoras organizou a disposição dos instrumentos musicais, e o palco no pátio do CEI, aos poucos, transformava-se num espaço preparado para um sarau musical.

No chão do pátio, perto do palco, lá estava outra pesquisadora criando um mapa, um território, um espaço: a terra/chão do mundo da dança. Lá estava, colando pedaços de papel $k r a f t$ a fim de formar um lugar mínimo, que pudesse deixar à vontade aqueles pequenos corpos. E por que não um linóleo, já que estamos falando em movimento/dança? Nada de linóleo, pensamos, o chão de papel era crucial; serviria de memória para o que iria acontecer. Canetas coloridas também foram convidadas a compor o espaço para o movimento/dança, e para além do papel - a imaginação, a brincadeira e os corpos, invocados a ocuparem o mesmo universo.

Não muito longe, também no pátio da escola, estava ainda outra pesquisadora, deixando as argilas prontas para serem amassadas, cortadas, moldadas e sentidas. Em algumas mesas próprias para o tamanho das crianças as argilas foram colocadas, dispostas como um convite à brincadeira. Cuidadosamente a pesquisadora desembalava as argilas para que, em breve, ícones fossem cunhados ali por mãos pequenas e curiosas, mãos que sentiriam uma carga de experiências.

Precisávamos ouvir as crianças, coletar suas impressões, deixar que nos falassem sobre a Mostra e sobre o que seus corpos/mentes quisessem nos comunicar. Estávamos abertas a 
escutar/ler/ver/sentir. Nós, envoltas na ansiedade de nos constituirmos em mediadoras de fato, estávamos atentas aos detalhes. Outra pista/ideia: livros de assinaturas. Mas crianças de 4 e 5 anos já sabem escrever? A maioria não, contaram-nos as professoras do CEI. Então, como seria o livro? Ideias daqui, ideias dali, definimos que tudo poderia ser de forma lúdica. Ir mar adentro no oceano das infâncias. E então criamos livros/cadernos com papel cartolina de várias cores, com páginas e páginas para que as crianças pudessem ali deixar suas marcas: escritas espelhadas, garatujadas, rabiscadas, manchadas, desenhadas, rasgadas etc.

Folhas e capas coloridas amarradas com fios de cetim, sem linhas, sem indicações, sem limite. Naquele momento de criação e brincadeira, que para a criança é algo sério, os livros/cadernos se tornaram a porta para um lugar mágico, para transportar da mediação para outro momento, sempre diferente e próprio de cada sujeito, nesse caso as crianças, criando o seu tempo-jogo, o seu tempo-lúdico. Um jogo do faz de conta, um jogo da espera e da descoberta (MARTINS, 2005).

Pensamos nesses livros/cadernos como uma proposta educacional sensível de reconhecimento do que seria aquele dia de mediações. Pensamos em uma proposta educacional, que, segundo Moraes e Navas (2015, p. 21),

\footnotetext{
[...] exige também a articulação das diferentes percepções, emoções, intuições com a razão, condição fundamental para a compreensão da multidimensionalidade humana, da nossa condição sapiens e demens, já que somos feitos de poesia e de prosa, de intuição, razão, emoção e sentimento, integrando corpo, mente e espírito. É preciso pensar em novas estratégias educativas que não estejam apenas preocupadas em desenvolver a aprendizagem dos fatos e eventos externos ao indivíduo, mas que também promovam o autoconhecimento, o reconhecimento do outro, o desenvolvimento da sensibilidade, da escuta-sensível e da autoestima.
}

Assim, o livro de assinaturas findaria as provocações das mediações culturais em dança, artes visuais e música, incorporando aos processos criativos das crianças outras formas de registrar e se perceber partícipes no ambiente educacional.

\section{MEDIAÇÃO CULTURAL: UM FAZER-SABER E SABER-FAZENDO}

A mediação cultural no contexto da pesquisa, que ora se apresenta como artigo, é considerada uma forma de intervir, de mobilizar interpretações de determinada realidade, objeto ou fenômeno que o sujeito contempla, estranha, acolhe e (re)significa. Na mediação cultural é possível compreender a educação como uma ação de interlocução não neutra, de troca, de se tornar parte do processo, de tomar parte, de compartilhar conhecimentos, de permitir e se permitir conhecer o outro. 
Ao iniciar a mediações culturais no CEI fomos à sala das crianças para convidá-las a fazer um percurso pela Mostra. Nas mãos das professoras elas vinham embaladas pelo som da flauta soprada por uma das pesquisadoras, adentrando um antigo/novo corredor, agora desconhecido, que se anunciava para ser desbravado, tateado, visto e sentido. Como diz Martins (2014, p. 39), "o corpo e a imaginação inventam espaços e criam lugares". E aquele espaço do corredor não cotidiano deu vida à Mostra, convidando-nos a ser, conhecer, fazer, sentir, pensar e agir.

E lá estávamos nós, pesquisadoras, em meio às fotos/imagens que constituíam a Mostra, esperando as professoras e as crianças num espaço transformado e dedicado a elas. Martins (2014, p. 39) conforta essa nossa ansiedade:

Também o corpo é provocado quando um olhar estrangeiro pode transformar um lugar familiar, como visitar uma casa, um parque, um bairro de nossa infância. Tanto lá como cá, o estranhamento só pode acontecer se adentramos no estado da vigília criativa, da sensibilidade à flor da pele. O passaporte é o corpo aberto, escancarado, em estesia, não anestesiado.

As crianças chegaram com passinhos, empurrões e curiosidade. "O que é isso? O que é isso?", perguntavam. "São fotos”, respondiam algumas. "Uma foto bem velha, né?", argumentou uma menina. "Olha! Uma bicicleta aqui”, dizia outra, e um menino respondeu: "Essa foto é de uma casa no mato"; ainda não sabiam que era a casa era um museu. As crianças seguravam as fotos/imagens com as duas mãos, para sentir bem, ver bem. Será que as crianças também buscavam pistas de algo? Elas rodavam e circulavam entre as fotos, uma disse: "Tem dos dois lados!".

Os olhares se voltaram para nós; parecia que as crianças queriam respostas, como nós havíamos previsto. E de prontidão, mas sem saber bem ao certo, lançamos algumas questões às crianças, pois não queríamos simplesmente responder, queríamos provocar. Indagamos: “Sabem de quem são essas fotos?". Silêncio, risadinhas, olhares entre vistas do colega, nada. Respondemos: "São fotos de um Museu Casa de um artista. Alguém sabe quem é o artista?". De repente alguém pergunta: "Ele está por aqui?", "Vamos procurá-lo...”, dizia outra criança. E assim seguimos no processo de mediação, questionando mais do que respondendo.

A Mostra de fotos/imagens virou jogo, busca e brincadeira, virou expedição, uma viagem por lugares que primavam novas e outras percepções. Como nos falam Moraes e Navas (2015, p. 21),

[...] apesar de não percebermos ou não valorizarmos a aprendizagem natural intrínseca ao nosso viver/conviver, ela está presente em nossas memórias, em nossos processos autoformativos, heteroformativos ou ecoformativos conscientes ou inconscientes, presentes em nossas experiências de vida, a maioria delas não reconhecidas ou não integradas aos processos de formais de educação. Tais aprendizagens influenciam e, 
muitas vezes, direcionam os processos de formação do sujeito apreendente, já que não é possível controlar todos os aspectos da formação humana. [...] Há sempre uma ligação entre o que produz a aprendizagem, o que potencializa a experiência e o que dá sentido a ela.

Assim, tomadas pelo encantamento, as crianças estavam na Mostra e ao mesmo tempo longe, na imaginação, na curiosidade, movendo-se num “[...] brincar viageiro por lugares visíveis e invisíveis, especialmente quando provocados para experiências estéticas" (MARTINS, 2014, p. 42).

A ideia da mediação cultural durante a Mostra de fotos/imagens foi sempre a de mobilizar as crianças para que criassem suas próprias impressões a partir das linguagens/expressões apropriadas pelo artista, como a modelagem, o desenho, e outras com as quais ele se identificava, como a música e até mesmo a questão corporal.

O artista apresentado na Mostra trabalhava o detalhamento e a expressão corporal de formas marcantes, o que se vê refletido em suas obras. "[...] Costumava trabalhar ouvindo Beethoven e Chopin” (ROSSI, 2014, p. 48), especialmente quando esculpia; tanto é que criou um busto do artista Beethoven, modelado numa postura romântica, “[...] como se fora vivo, a expressão austera e turbulenta das paixões da vida, a cabeleira revolta captada num átimo do tempo" (GUERREIRO apud ROSSI, 2014, p. 53).

Continuando a mediação, foram propostas atividades para que as crianças vivenciassem outros sentidos: primeiro com a argila, convidando as crianças a inventar. “O que é para fazer?”, perguntou alguém lá no cantinho da mesa. "Tudo o que você quiser, a argila é sua, o que você quer fazer?", respondeu uma das pesquisadoras. Uma confirmação, será que era isso que aquela criança queria? Suas mãos já estavam em meio à argila, a vontade de fazer aquilo que nem ela nem ninguém sabia ainda era mais forte que o esperar a resposta. Arregaça manga daqui, tira casaco dali, terra no rosto, na orelha, no nariz, uma festa havia começado. De repente uma criança exclamou: "O meu se chama Vítor, é um super-herói, mas só a cabeça que eu fiz, aqui é a boca, aqui os olhos, Vítor". Esses processos de aprender e sentir nos remetem ao pensamento de Duarte Jr. (2010, p. 157):

[...] tomar o sensível como fundamento de um processo educacional, portanto, não tem a ver apenas com os níveis elementares da educação, com a formação da criança e do jovem exclusivamente, mas pode se estender ao longo da vida dos indivíduos e da sociedade como um todo.

A música, amparada pelas palavras de Duarte Jr. (2010), já estava ressoando, embalandonos para um outro espaço preparado no palco do CEI. Ao chegar a esse local, as crianças depararam com diversos instrumentos musicais. Nada lhes foi dito, pois esperávamos o 
primeiro contato delas, pegando, batendo, chacoalhando, balançando, tocando os instrumentos. Elas não sabiam o que fazer primeiro, rapidinho uma briga ou outra precisou ser apartada: "Quero esse, me dá", ouvimos. No teclado, que seria o espaço da pesquisadora, já estavam algumas crianças. O teclado era grande, cabia mais de uma criança, fazendo sons diferentes dependendo o lugar onde se tocava, transformando-se num grande brinquedo.

Era a hora da música, entravam em cena instrumentos como sinos, guizos, ovinhos, recoreco, triângulos, clavas e tantos outros. Rapidamente cada criança tinha um instrumento nas mãos, elas estavam agitadas, curiosas, saboreando, ouvindo e tocando, descobrindo o som a sua maneira. Começara a festa-orquestra, começara a brincadeira-banda. Demorou um pouco para as crianças encontrarem o seu ritmo, nós não queríamos intervir, a atitude e o tempo pertenciam a elas, que, sabíamos nós (teoricamente até então), iriam sozinhas encontrar outros lugares - os lugares musicais. E como bem nos alerta Penna (2015, p. 31), “[...] musicalizar é desenvolver os instrumentos de percepção necessários para que o indivíduo possa ser sensível à música, apreendê-la, recebendo material sonoro/musical como significativo".

Em seguida, a voz de uma das pesquisadoras foi mais alta: é hora da música! Sem demora as crianças voltaram seus olhos e ouvidos à ela, que disse: "Quando nós fizermos assim [gesto], é para tocar; quando fizermos assim [outro gesto], é para parar. Opa, um, dois e três, agora! Mais uma vez! Agora!”. Mexe e mexe, bate e bate, chacoalha. Tudo virou brincadeira. Tudo virou coreografia. A pesquisadora voltou para o teclado, e ao som dele as crianças se mexiam e remexiam. Som dali, som daqui, tudo se intercruzava: a música, a dança e o visual. Acompanhar o som vindo de lá era um desafio para todos nós.

E lá fomos nós para a próxima experiência - a dança, o movimento e outras descobertas. Uma das pesquisadoras iniciou as articulações em movimento/dança em cima do papel kraft mais espesso colado no chão, para que aguentasse a sua intervenção de todo jeito e nunca de um jeito só. Mas primeiro era preciso sentir o chão, ficar descalço.

$\mathrm{Na}$ mediação cultural em movimento/dança decidimos mudar a organização dos corpos no espaço para olhar de cabeça para baixo. Andar de lado, rodar, pular, virar devagar como em câmera lenta, cair, correr e cair de novo, arrastar-se e sentir, sentir fazendo o corpo ficar diferente. Organizar o corpo no espaço diferente do habitual. Ver com o corpo em movimento, sentir que o corpo é mais, pode mais, muito mais. Nesse momento Maldonato (2012, p. 27) corrobora ao dizer: “[...]: nossa civilização está reaprendendo a sentir com o corpo". Se assim for, queremos fazer parte dessa dança!

A maneira como nós ficamos com o nosso corpo, seja sentado, em pé, no chão, de braços cruzados, de cabeça baixa ou ao se esparramar numa carteira, por exemplo, significa que 
estamos dizendo algo, pedindo algo, negando algo ou alguém e isso se repete para tudo que o corpo comunica, para com tudo que o corpo conversa. Nesse diálogo coreográfico, o corpo com a sua ressonância estabelece o tipo de relação que se tem com o mundo, com o outro e consigo mesmo.

O corpo está impregnado de subjetividade, e não é algo que se possui descolado ou desconectado do "eu" como um objeto ou uma ideia que se pode esquecer. O corpo é o eu, somos corpo-sujeito. Apesar de oscilarmos constantemente entre ter um corpo e ser um corpo, diz Maldonato (2012, p. 27): “[...] eu sou inescapavelmente meu corpo”. Somos corpo e movimento, corpo e sentimento, corpo e ação.

Já que a música estava presente no ato de dançar, pensamos: Por que não desenhar com o corpo, unir a dança e o movimento com as artes visuais? Sem demora o papel se fez necessário para coreografar/registrar o caminho do movimento por onde nossos dedos passavam, por onde nossos pés caminhavam, por onde nosso corpo, quando de encontro com outros corpos, transitava.

Logo, o papel kraft, marrom e aparentemente sem graça, ganhou cor e vida. O movimento pôde ser eternizado para virar arte/dançante. Nesse processo, entre corpo, diálogo e interação, ao som da música tocada por outra pesquisadora (entre o clássico e o popular), com a caneta colorida em uma das mãos, as crianças traçaram o movimento. Algumas vezes acompanhando o som da música e outras vezes acompanhando o som do seu próprio corpo, o som interior. Barulhinho de pé no papel, o movimento tomou consciência e todos queriam fazer a dança mesmo atrasados, o tempo não existia mais. De repente uma menina disse: "Meu, que legal!".

As crianças, então, foram convidadas a passar novamente pela Mostra, para dar uma última olhada nas fotos/imagens, talvez pegar um instrumento musical, talvez se jogar de novo no papel kraft, talvez dar aquela última mexida na escultura que criaram. Deixamos que as crianças finalizassem a mediação, e logo uma delas perguntou: "Professora, por que tem aqueles cadernos ali com canetinha?". Foi a deixa, o grandfinale. Respondemos quase em coro: "Para que vocês deixem para nós suas assinaturas, recadinhos, desenhos, o que quiserem". Como pesquisadoras/cartógrafas podemos dizer que a mediação cultural e todo o seu processo (antes, durante e depois) foi uma experiência de vários sentidos, repleta de fazeres, dizeres e cantares.

\section{6 (IN)CONCLUSÃO}

Neste trajeto final, retomamos a indagação inicial da pesquisa: Como pensar e fazer mediação cultural na educação infantil, tendo a cartografia atravessada pelas 
linguagens/expressões da arte na construção de sentidos? Pergunta sem resposta definitiva, pois a criança aprende enquanto experimenta, descobre e inventa num processo contínuo e sem fim.

Podemos apenas dizer que as crianças construíram sentidos, vivendo, construindo encontros com as sonoridades, com o corpo/movimento, com o visual, com o tátil, enfim, com a experiência. Especialmente nesse momento de infância, a articulação das múltiplas linguagens/expressões é fundamental nos processos de ser e de aprender.

Mas, qual é o critério de avaliação do cartógrafo? É o “[...] grau de intimidade que cada um se permite, [...] é, fundamentalmente, o grau de abertura para a vida que cada um se permite a cada momento" (ROLNIK, 2016, p. 68). O critério de avaliação está no que se permite ver, como se permite ver a criança. Corre-se o risco de ter interpretações sempre muito diversas, quando se fala de ver a infância. É por isso que o trato, cuidado do cartógrafo esteja no princípio de ser extramoral, ou seja, “[...] pode-se até dizer que se princípio é um antiprincípio: um princípio que obriga a estar sempre mudando de princípios" (ROLNIK, 2016, p. 68). Estamos falando de abertura ao novo, na reorientação constante dos afetos que acontecem no processo de pesquisar envolvendo o humano, a criança.

E, na cartografia, que dados são coletados? Existem dados a coletar? Quando se trata da cartografia é preciso esclarecer o que é um dado para um cartógrafo. Como a cartografia consiste em acompanhar processos que se alteram, estes fazem "[...] emergir realidades que não estavam 'dadas', à espera de observação" (BARROS; BARROS in PASSOS; KASTRUP; TEDESCO, 2014, p. 175). A pesquisa não cumpre um roteiro pré-estabelecido e não finda com um roteiro, esse roteiro existe a priori, mas tanto quanto os processos; é alterado no decorrer dos movimentos percebidos. Há também, nessas mudanças, uma temporalidade que também deve ser elencada como vital ao cartógrafo, é pensar sempre que as coisas se alteram no tempo.

É preciso esclarecer que a pesquisa que envolve a cartografia é esse rearranjar de territórios e de espaços, fala-se de fronteiras entre o que é da infância, o que é da escola, o que é da família, o que é da casa, da família, o que é de quem? Quem é o que? Ou seja, fronteiras estabelecidas entre sujeito e objeto. Dissolver essas fronteiras pré-estabelecidas e perceber novas está no plano da cartografia. Perceber os problemas, criar dúvidas, duvidar. Sua função é gerar e perceber efeitos, e não especificamente dados para serem coletados, quantificados.

É evidente que qualquer tipo de avaliação nessa categoria inventada, a infância, envolvendo a cartografia, segundo Rolnik (2016, p. 68-69): 
que o corpo vibrátil capta no ar: uma espécie de feeling que varia inteiramente em função da singularidade de cada situação, inclusive do limite de tolerância do próprio corpo vibrátil que está avaliando, em relação à situação que avalia. A regra do cartógrafo, então, é muito simples: é só nunca esquecer de considerar esse "limiar"”.

Estávamos desafiando esse limiar, tão difícil de manter sem escapar para conclusões apressadas e imediatistas. Estávamos invariavelmente fazendo uma engenharia de sentidos, ajustes finos, como quem se utiliza de uma lupa de ourives, na mão de um pesquisador, envolvendo algo tão frágil quanto as infâncias.

Mas o que se analisa, então, em cartografia? "Analisar é, assim, um procedimento de multiplicação de sentidos e inaugurador de novos problemas" (BARROS; BARROS in PASSOS; KASTRUP; TEDESCO, 2014, p. 178). Analisar consiste em dar visibilidade às relações que se estabelecem/constituem em cada realidade que se apresenta e que envolve também o pesquisador. É permitir que a própria pesquisa seja interrogada, por meio de pistas e de efeitos percebidos.

Os efeitos desta investigação, narrados por meio de caminhos que percorremos, sempre buscando aprender com as experiências, apontaram algumas construções de sentidos pelas crianças em linguagens/expressões das artes. As pistas sinalizaram sentidos, sem a intenção de definir padrões, uma vez que na cartografia somos tomados sempre pelo (in)conclusivo, pelo (in)definido, sempre um devir que dependerá das relações que estabelecemos, dos caminhos percorridos ou a percorrer. Como asseveram Deleuze e Guattari (2010, p. 26),

num conceito, há, no mais das vezes, pedaços ou componentes vindos de outros conceitos, que respondiam a outros problemas e supunham outros planos. Não pode ser diferente, já que cada conceito opera um novo corte, assume novos contornos, deve ser reativado ou recortado.

Para os autores, o "conceito" é uma organização do pensamento. É um acontecimento no pensamento decorrente dos problemas que são "sentidos" muito antes do pensar. Os problemas são os motores do pensamento. E o pensamento, dessa forma, estará preenchido de imanência, ou seja, atravessado por vários elementos/circunstâncias que serão indissociáveis, mesmo em planos diferentes e imperceptíveis (DELEUZE; GUATTARI, 2010).

É por isso que optamos por falar de efeitos percebidos, em vez de estabelecer conceitos neste trajeto que finda. Nosso não conceitual tem muito de Larrosa $(2015$, p. 42): “[...] se a função dos conceitos [...] é tranquilizar o homem que consegue possuí-los, talvez querer chegar demasiado rápido ao conceito seja como querer se tranquilizar demasiado rápido". E é por isso que nós não queremos ter pressa. Como sujeitos da experiência, pensamos em dar tempo ao tempo, contrariando o exposto universal de noção temporal, essa maré que nos toma fazendo 
do tempo um negócio.

Os processos experienciados na pesquisa apontam algumas construções de sentido das crianças por meio das linguagens/expressões da arte. No que se refere à música, foi possível destacar alguns processos das crianças, como: identificação de diferentes instrumentos musicais; percepção das distintas sonoridades dos instrumentos tocados por elas; escuta dos sons produzidos de forma individual e/ou coletiva; construção de outras sonoridades a partir da escuta; e criação musical, conforme o gestual da regência das músicas propostas, em que tocaram e cantaram durante as mediações, mesmo sem ter tido acesso à leitura musical rítmica e melódica.

Nas artes visuais os processos foram os seguintes: relação objeto espaço; contato tridimensional e percepção das dimensões (curto/comprido, fino/grosso, largo/estreito, vazio/cheio, leve/pesado, volume); identificações sensoriais com relação às texturas (quente/frio, molhado/seco, úmido, mole/duro, áspero/liso); e leituras de imagens com relação à percepção das cores, do traço, da forma, do conteúdo.

$\mathrm{Na}$ dança identificamos nas crianças a relação do corpo com o espaço; do corpo com outros corpos; do corpo com o movimento; do corpo com os ritmos musicais; o corpo liberto, o corpo falante, o corpo extrapolando limites; o corpo numa dança lúdica, o corpo criativo, o corpo que comunica, que descobre possibilidades de movimentos; o corpo que expressa sentimentos e sentidos, o corpo que se expande, que pensa.

Percebemos que a dança atravessou a música e as artes visuais, as artes visuais atravessaram a dança e a música atravessou as artes visuais e a dança. Uma atravessando a outra, misturando-se num miscigenar de cores, tons, ritmos, cheiros e formas.

Outro aspecto a ser considerado foi a utilização dos espaços que o CEI oferece, muitas vezes usados apenas como refeitório, como descanso ou outra finalidade. Tais espaços estavam repletos de identidades, de elementos que poderiam a qualquer tempo ser (re)significados em movimentos de sentires. $\mathrm{O}$ espaço tem essa potencialidade e necessita apenas ser apropriado, tomado de sentidos por nós. Significamos também os espaços quando colocamos em prática a curadoria - deslocando as ideias do papel para o espaço, que culminou na Mostra.

Escolhas, decisões, discussões, argumentos fizeram parte dessa trajetória coberta por densas reflexões. Olhos curiosos desdobravam-se em achados e aprendizados sobre nossos corpos nos espaços envoltos por paredes, imagens/fotos, sinalizações, cheiros, sons e movimento. Crianças fazendo descobertas, deixando suas impressões e marcas nas linguagens/expressões da arte/vida.

Experiências multicores (entre)laçavam-se em vozes, corpos, movimentos, texturas, 
objetos e pessoas. Pessoas, criando a partir da experiência, sentidos, amorosidade, afetos, aprendendo com a vida - viver. Este talvez seja o maior desafio de uma pesquisa: o que ficou de nós para os outros e dos outros em nós.

\section{REFERÊNCIAS}

ALVES, Rubem. A alegria de ensinar. 3. ed. São Paulo: ARS Poética, 1994. . Do universo à jabuticaba. São Paulo: Planeta do Brasil, 2010. . Educação dos sentidos e mais... Campinas: Verus, 2005.

BARBOSA, Ana Mae. Mediação cultural é social. In: ; COUTINHO, Rejane Galvão (Orgs.). Arteleducação como mediação cultural e social. São Paulo: Editora UNESP, 2009. p. $13-22$.

BOFF, Leonardo. A águia e a galinha: uma metáfora da condição humana. Petrópolis: Vozes, 1997.

CHIARELli, Tadeu. (Coord.). Grupo de estudos em curadoria. São Paulo: Museu de Arte Moderna, 1998.

DELEUZE, Gilles; GUATTARI, Félix. O que é a filosofia? 3. ed. Tradução de Bento Prado Jr. e Alberto Alonso Muñoz. São Paulo: 34, 2010.

DEMARCHI, Rita de Cássia. Encontros sensíveis: experiências de mediação da obra pública Estação Sumaré no metrô de São Paulo. 2003. Dissertação (Mestrado em Artes Visuais)Instituto de Artes, Universidade Estadual Paulista, São Paulo, 2003.

DUARTE JR., João Francisco. O sentido dos sentidos: a educação (do) sensível. 5. ed. Curitiba: Criar Edições, 2010.

FAZENDA, Ivani Catarina Arantes (Org.); GODOY, Hermina Prado (Coord.). Interdisciplinaridade: pensar, pesquisar, intervir. São Paulo: Cortez, 2014.

FLICK, Uwe. Introdução à pesquisa qualitativa. 3. ed. Tradução de Joice Elias Costa. Porto Alegre: Artmed, 2009.

GEERTZ, Clifford. A interpretação das culturas. Rio de Janeiro: LTC, 1989.

KASTRUP, Virgínia. A invenção de si e do mundo - uma introdução do tempo e do coletivo no estudo da cognição. Campinas: Papirus, 1999.

LARROSA, Jorge. O enigma da infância ou o que vai do impossível ao verdadeiro. In:

Pedagogia profana: danças, piruetas e mascaradas. Tradução de Alfredo Veiga-Neto. 5. ed. Belo Horizonte: Autêntica, 2013. p. 183-198.

. Tremores: escritos sobre experiência. Tradução de Cristina Antunes e João Wanderley 
Geraldi. Belo Horizonte: Autêntica, 2015. (Educação: experiência e sentido).

LEITE, Maria Isabel; OSTETTO, Luciana Esmeralda (Orgs.). Museu, educação e cultura: encontros de crianças e professores com a arte. Campinas: Papirus, 2005.

MALDONATO, Mauro. Passagens de tempo. Tradução de Roberta Barni. São Paulo: Sesc, 2012.

MARTINS, Mirian Celeste. Expedições instigantes. In: ; PICOSQUE, Gisa. Mediação cultural para professores andarilhos na cultura. São Paulo: Intermeios, 2012a.p. 7-23.

- Mediação: primeiros encontros com arte e cultura. In: ; PICOSQUE, Gisa.

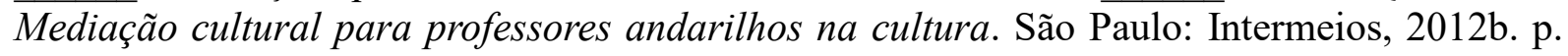
24-42.

. Mediação: provocações estéticas. Revista Mediação, São Paulo, v. 1, n. 1, out. 2005.

(Org.). Pensar juntos mediação cultural: [entre]laçando experiências e conceitos. São Paulo: Terracota, 2014. (Arte, educação e cultura).

MINAYO, Maria Cecília de Souza (Org.). Pesquisa social: teoria, método e criatividade. 34. ed. Petrópolis: Vozes, 2015.

MORAES, Maria Cândida; NAVAS, Juan Miguel Batalloso (Colab.). Transdisciplinaridade, criatividade e educação: fundamentos ontológicos e epistemológicos. Campinas: Papirus, 2015. (Práxis).

OBRIST, Hans Ulrich. Uma breve história da curadoria. Tradução de Ana Resende. São Paulo: BEI Comunicação, 2010.

OSTETTO, Luciana Esmeralda; LEITE, Maria Isabel. Arte, infância e formação de professores: autoria e transgressão. 7. ed. Campinas: Papirus, 2012.

PASSOS, Eduardo; KASTRUP, Virgínia; ESCÓSSIA, Liliana da (Orgs.). Pistas do método da cartografia: pesquisa-intervenção e produção de subjetividade. Porto Alegre: Sulina, 2014.

PASSOS, Eduardo; KASTRUP, Virgínia; TEDESCO, Silvia (Orgs.). Pistas do método da cartografia: a experiência da pesquisa e o plano comum. Porto Alegre: Sulina, 2014.

PENNA, Maura. Música(s) e seu ensino. 2. ed. Porto Alegre: Sulina, 2015.

ROLNIK, Suely. Cartografia sentimental: transformações contemporâneas do desejo. 2. ed. Porto Alegre: Sulina; Editora da UFRGS, 2016.

ROSSI, Juliana. Artes visuais de Joinville e o blog como mediador cultural. 2014. 203 f. Dissertação (Mestrado em Educação)-Universidade da Região de Joinville, Joinville, 2014. Disponível em: <http://univille.edu.br/community/mestrado _ed/VirtualDisk.html?action=readFile\&file=Dissertacao_Juliana_Rossi.pdf\&current=/Dissert acoes_turma_II $>$. Acesso em: 9 set. 2015. 
ROWLING, Joanne K. Harry Potter e o prisioneiro de Azkaban. Tradução de Lia Wyler. Rio de Janeiro: Rocco, 2000.

TORDINO, Cláudio Antônio. A estética do método. In: FAZENDA, Ivani Catarina Arantes (Org.); GODOY, Hermina Prado (Coord.). Interdisciplinaridade: pensar, pesquisar, intervir. São Paulo: Cortez, 2014. 